\title{
ANTIMICROBIAL RESISTANCE PROFILE OF ENTEROCOCCUS SPP ISOLATED FROM FOOD IN SOUTHERN BRAZIL
}

\author{
Gustavo Pelicioli Riboldi'; Jeverson Frazzon ${ }^{1,4 *}$; Pedro Alves d'Azevedo³; Ana Paula Guedes Frazzon²
}

${ }^{1}$ Programa de Pós-Graduação em Biologia Celular e Molecular, Centro de Biotecnologia, Universidade Federal do Rio Grande do Sul, Porto Alegre, RS, Brasil; ${ }^{2}$ Departamento de Microbiologia, Universidade Federal do Rio Grande do Sul, Porto Alegre, RS, Brasil; ${ }^{3}$ Departamento de Microbiologia, Universidade Federal de Ciências da Saúde de Porto Alegre, Porto Alegre, RS, Brasil;

${ }^{4}$ Instituto de Ciência e Tecnologia de Alimentos, Universidade Federal do Rio Grande do Sul, Porto Alegre, RS, Brasil.

Submitted: July 11, 2007; Returned to authors for corrections: February 13, 2008; Approved: November 20, 2008.

\begin{abstract}
Fifty-six Enterococcus spp. strains were isolated from foods in Southern Brazil, confirmed by PCR and classified as Enterococcus faecalis (27), Enterococcus faecium (23) and Enterococcus spp (6). Antimicrobial susceptibility tests showed resistance phenotypes to a range of antibiotics widely administrated in humans such as gentamycin, streptomycin, ampicillin and vancomycin.
\end{abstract}

Keywords: Enterococcus spp, antibiotic resistant enterococci, food

Enterococcus spp. are Gram-positive bacteria able of growing and surviving under harsh conditions. They are ubiquitous in nature being present in soil, waters, raw plant and animal products. Enterococci are natural component of foods, representing important role in ripening and flavor enhancement of cheese and sausage. They have been used as probiotics to improve the microbial balance of the intestinal tract in humans and animals. Despite the fact that the Enterococcus genus is responsible for beneficial effects in foods, they are not considered "generally recognized as safe" (GRAS), due to its use as an indicator of fecal contamination, and the frequent association with food-borne illnesses by biogenic amines production $(6,14)$. An important clinical feature of Enterococcus spp. is the resistance to a wide range of antimicrobial agents as demonstrated in clinical, food and water isolates strains $(4,7,8)$. In addition, these bacteria are able to acquire resistance determinants through gene transference by plasmids and transposons. The use of antimicrobials in animal feed as growth promoters have created large reservoirs of transferable antibiotic resistance genes in several ecosystems, and consequently a possible route transmission of resistant Enterococcus spp. via food chain could be suggested (17). In this way, the aim of the present study was to determine the species distribution and the antibiotic resistance patterns of enterococci isolated from in natura food and dairy products in Porto Alegre, Southern Brazil.

The enterococcal strains were isolated from cassava, beetroot, potato, sweet potato, parsley, cabbage, raw meat, pasteurized milk and dairy products, such colonial cheese type and soft cheese. Food samples were purchased from different popular markets in Porto Alegre, Brazil. The Enterococcus spp. isolation, characterization and identification methodology was carried out as previously described by Domig et al. (2). The first isolation step consisted of inoculation of $25 \mathrm{~g}$ of food in sterile buffered peptone water $(225 \mathrm{ml})$ and incubation at $37^{\circ} \mathrm{C}$ for $16 \mathrm{~h}$. From this suspension, $125 \mu \mathrm{l}$ were plated on brain heart infusion (BHI) agar, supplemented with $0.02 \%$ azide and $6,5 \%$ $\mathrm{NaCl}(\mathrm{w} / \mathrm{v})$ and incubated at $37^{\circ} \mathrm{C}$ for $72 \mathrm{~h}$. Phenotypic criteria (such as size/volume, shape, color, hemolytic profile) were used for strains isolation and colony picking of presumable streptococcal/enterococcal strains. Phenotype tests were used to separate the enterococci group and the non-enterococcal strains. Colonies with typical enterococci morphology were identified to genus level by the following methods: Gram staining, catalase production and esculin hydrolysis tests in combination with resistance to bile salts, production of

*Corresponding Author. Mailing address: Centro de Biotecnologia, Campus do Vale - UFRGS. Av. Bento Gonçalves 9500 - Prédio 43431 - Lab. 209. PO Box: 15005 - Porto Alegre, RS, Brasil. Tel.: +5551 33086072, Fax: +5551 33087309. E-mail: jeverson.frazzon@ufrgs.br 
pyrrolidonylarylamidase (PYR test) and growth at $10^{\circ} \mathrm{C}$ and $45^{\circ} \mathrm{C}$. The selected strains were stored in BHI containing $50 \%$ glycerol at $-20^{\circ} \mathrm{C}$. Fifty six previously isolated Enterococcus spp. were submitted to Polimerase Chain Reaction (PCR) using genusspecific primer pair of the tuf gene, which targeted and amplified a 112 base pair (bp) DNA fragment. Reactions were carried out as described by Ke et al. (12). Genomic DNA was extracted by the boiling method, as described by Hagen et al. (9). Strains isolated were subjected to species identification by phenotype characterization according to the protocol proposed by Facklam et al., (5). The trial assay included: presence of arginine and pyruvate dehydrolases; acid production from $1 \% \mathrm{~L}$-arabinose, raffinose, mannitol, $\alpha$-methyl-D-glucopyranoside, sorbitol and L-sorbose; motility and pigmentation characteristics. Enterococcus faecalis ATCC 51299 and Staphylococcus aureus (ATCC 25923) were used as control strains. Antimicrobial susceptibility was determined using the disk diffusion, according to the recommendations of NCCLS (16). Twelve antibiotics commonly used in the treatment of clinical infection and agricultural procedures were tested (concentrations are expressed in $\mu \mathrm{g} \mathrm{ml}^{-1}$ ): ampicillin-10 (AMP), vancomycin-30 (VAN), erythromycin-15 (ERI), tetracycline-30 (TET), ciprofloxacin-5 (CIP), norfloxacin-10 (NOR), nitrofurantoin-300 (NIT), cloramphenicol- 30 (CLO), gentamycin-120 (GEN), streptomycin-300 (ET), quinupristin-dalfopristin-15 (QD), bacitracin - 0,04UI (BC) and lincomycin-15 (MY). The appropriate antibiotic dosage was purchased from Oxoid (Hampshire, United Kingdom), bioMérieux (Marcy-l'Etoile, France) and Difco (Detroit, USA). Inhibition zone diameters were measured and strains were classified according to the criteria from NCCLS (for AMP, VAN, ERI, TET, CIP, NOR, NIT, CLO, GEN, ET, QD) and Hart et al. (10) and Moyaert et al. (15) (for BAC and MY).

A total of $150 \mathrm{Gram}$-positive and catalase negative cocci were isolated from vegetables, raw meat, pasteurized milk and dairy products during March to July, 2005. Among these isolates, 82 strains were classified as Enterococcus spp. by phenotypic methods, and to grow at $45^{\circ} \mathrm{C}$ and in the presence of $6.5 \% \mathrm{NaCl}$, after $48 \mathrm{~h}$ of incubation. All 82 strains were tested using a genusspecific primer for the tuf gene. Fifty-six isolates were confirmed as Enterococcus genus by PCR amplification. Species characterizations were performed and the strains were classified as E. faecalis (27 strains), Enterococcus faecium (23 strains), Enterococcus spp (6 strains) (Fig. 1). In the vegetables group $E$. faecium was the most abundant species detected, mainly in beetroot and potato (100\%) and parsley $(80 \%)$, whereas E. faecalis was observed in cabbage (65\%). These data's are in agreement which has been described by Abriuoel et al., (1). Only cassava and sweet potato did not present any Enterococcus spp.

In raw meat and colonial cheese type strains of E. faecalis was the most prevalent species, which could be explained by the fact that these foods are manipulated by hands suggesting a contamination during the manufacturing process. Otherwise,

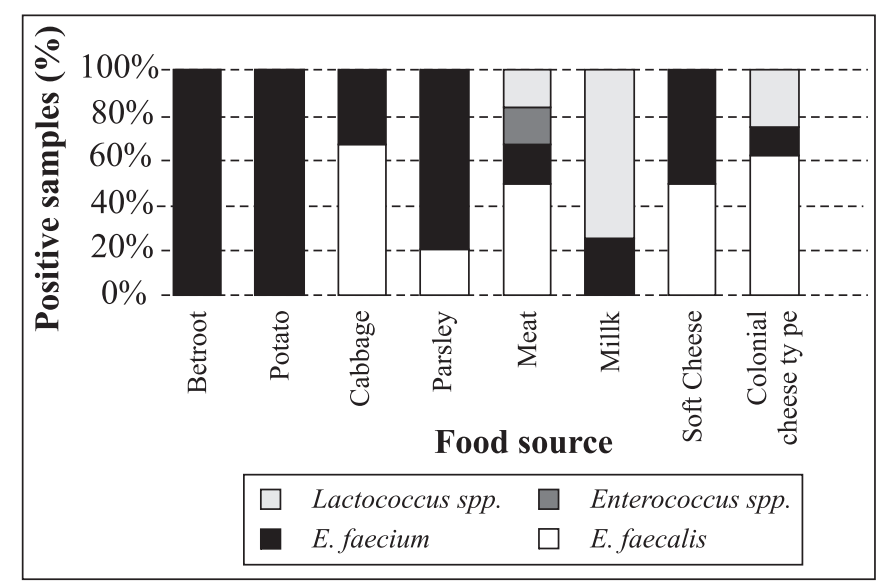

Figure 1. Percentage distribution of Enterococcus species isolated from food in Porto Alegre, Brazil.

in pasteurized milk nearly all microorganisms get (around 80\%) was Lactococcus spp. go behind by E. faecium. The presence of the bacteria $E$. faecium in processed milk is explained by often capable of these microorganisms survives during pasteurization process (18).

Antibiotic susceptibility tests of Enterococcus spp. isolated are shown in Table 1. Almost all enterococcus strains displayed resistance to at least one antibiotic tested, with the exception for milk isolates where all strains were susceptible. Resistance to antimicrobials commonly used in agriculture such as bacitracin (34 strains) and lincomycin (12 strains) showed relatively high frequency of occurrence. Resistance to nitrofurantoin, antibiotic used for treatment of genitourinary tract infections, was observed among isolates strains from soft cheese and cabbage. However, none of the Enterococcus spp. strains was resistant to norfloxacin; drug used in urinary tract infection treatments. Enterococcus isolated from cabbage showed the resistance to several of antimicrobials used in human medicine such as tetracycline, ciprofloxacin, nitrofurantoin and quinupristin/ dalfopristin. Elevated amount of High-Level of Aminoglycosides Resistance (HLAR) was observed in both E. faecalis and $E$ faecium strains from all foods samples analyzed.

Three E. faecalis strains isolated from cheese and meat showed ampicillin-resistant (AMPR) pattern, a clinical relevant antibiotic since ampicillin remains the drug of choice for the treatment of enterococcal infections. Furthermore, a combination of cell-wall active agent and aminoglycoside (e.g. ampicillin + gentamicin) is the selective treatment for enterococcal endocarditis (13). Moreover, in colonial cheese type it was detected the presence of one $E$. faecalis vancomycin-resistant (VRE) strain. This finding is the most relevant in this study and serves as warning to authorities of public healthy since vancomycin is the last antibiotic alternative utilized for treatment of nosocomial infections. 
Table 1. Antibiotic resistant phenotypes of Enterococcus species isolated from food.

\begin{tabular}{cccccccccc}
\hline \multirow{2}{*}{ Antimicrobial agent } & \multicolumn{3}{c}{ E. faecalis $(\mathrm{n}=27)$} & \multicolumn{3}{c}{ E.faecium $(\mathrm{n}=23)$} & \multicolumn{3}{c}{ Enterococcus spp. $(\mathrm{n}=6)$} \\
\cline { 2 - 10 } & $\mathrm{S}(\%)$ & $\mathrm{I}(\%)$ & $\mathrm{R}(\%)$ & $\mathrm{S}(\%)$ & $\mathrm{I}(\%)$ & $\mathrm{R}(\%)$ & $\mathrm{S}(\%)$ & $\mathrm{I}(\%)$ & $\mathrm{R}(\%)$ \\
\hline AMP (a) & 88,9 & 0 & 11,1 & 23 & 0 & 0 & 100 & 0 & 0 \\
VAN (a) & 88,9 & 7,4 & 3,7 & 23 & 0 & 0 & 100 & 0 & 0 \\
ERI(a) & 77,8 & 11,1 & 11,1 & 52,2 & 34,8 & 13 & 0 & 66,6 & 26,4 \\
TET (a) & 66,67 & 0 & 33,33 & 82,6 & 8,7 & 8,7 & 100 & 0 & 0 \\
CIP(a) & 63 & 29,6 & 7,4 & 78,3 & 21,7 & 0 & 33,3 & 50 & 16,7 \\
NOR(a) & 85,2 & 14,8 & 0 & 87 & 13 & 0 & 83,3 & 16,7 & 0 \\
NIT (a) & 100 & 0 & 0 & 87 & 0 & 13 & 83,3 & 0 & 16,7 \\
CLO(a) & 88,9 & 3,7 & 7,4 & 70 & 30 & 0 & 33,3 & 33,3 & 33,3 \\
QD (a) & -2 & -2 & -2 & 91,3 & 0 & 8,7 & 60 & 40 & 0 \\
GEN(a) $)^{l}$ & 77,8 & 0 & 22,2 & 87 & 0 & 13 & 100 & 0 & 0 \\
ET (a) ${ }^{l}$ & 77,8 & 3,7 & 18,5 & 87 & 3,7 & 9,3 & 100 & 0 & 0 \\
BC (b) & 0 & 40,7 & 59,3 & 0 & 39 & 61 & 0 & 16,7 & 83,3 \\
MY (b) & 48,1 & 0 & 51,9 & 91,3 & 0 & 8,7 & 100 & 0 & 0 \\
\hline
\end{tabular}

Ampicillin (AMP), vancomycin (VAN), erythromycin (ERI), tetracycline (TET), ciprofloxacin (CIP), norfloxacin (NOR), nitrofurantoin (NIT), cloranphenicol (CLO), quinupristin-dalfopristin (QD), gentamycin (GEN), streptomycin (ET), bacitracin (BC) and lincomycin (MY). (a) NCCLS (14); (b) Hart et al. (8); Moyaert et al. (13); ${ }^{1}$ High level resistance; ${ }^{2}$ Not tested due to the intrinsic resistance of the species against the substance. Resistance profile: S: susceptible; I: intermediate; R: resistant.

Finally, one reason that could explain the emergence of antibiotic resistant enterococci in food samples would be the massive use of antibiotic in agriculture (e.g., avoparcin as animal growth promoters). Some studies have shown that the same resistance gene was found in bacteria isolated from both food samples and patients $(3,4)$. Experimental investigations showed that resistance plasmid pAM $\beta 1$ has been transferred among $E$. faecalis, E. faecium, and Lactobacillus reuteri in the digestive tracts of mice, and this plasmid has also been transferred between $L$. curvatus strains in fermenting sausages (14). These observations support the hypothesis that resistant enterococci can contaminate food, enter the human gastrointestinal tract and colonize humans and/or pass their resistance genes to commensal bacteria present in the human intestinal tract (7). Emergence of enterococci antimicrobial resistance and its spreading in food suggest a situation of risk for community, and also a possible correlation between strains present in hospitals with those isolated from food must be considered. Here, we described the first report of antibiotic resistant enterococci isolated from foods in Porto Alegre, Southern Brazil.

\section{RESUMO}

\section{Perfil de resistência antimicrobiana de Enterococcus spp isolados de alimentos no Sul do Brasil}

Cinqüenta e seis cepas de Enterococcus spp. foram isoladas de alimentos no Sul do Brasil, confirmados por PCR e classificadas como Enterococcus faecalis (27), Enterococcus faecium (23) e Enterococcus spp. (6). Testes de susceptibilidade aos antimicrobianos demonstraram fenótipos de resistência a uma gama de antibióticos administrados em humanos, como gentamicina, estreptomicina, ampicilina e vancomicina.

Palavras-chave: Enterococcus spp., enterococos resistentes a antimicrobianos, alimentos

\section{REFERENCES}

1. Abriouel, H.; Omar, N.B.; Molinos, A.C.; López, R.L.; Grande, M.J.; Martínez-Viedma, P.; Ortega, E.; Cañamero, M.M.; Glavez, A. (2008). Comparative analysis of genetic diversity and incidence of virulence factors and antibiotic resistance among enterococcal populations from raw fruit and vegetable foods, water and soil, and clinical samples. Int. J. Food Microbiol. 123: 38-49.

2. Domig, K.J.; Mayer, H.K.; Kneifel, W. (2003). Methods used for the isolation, enumeration, characterization and identification of Enterococcus spp. 2. Pheno- and geno typic criteria. Int. J. Food Microbiol. 88: 165-188.

3. Donabedian, S.M.; Thal, L.A.; Hershberger, E.; Perri, M.B.; Chow, J.W.; Bartlett, P.; Jones, R.; Joyce, K.; Rossiter, S.; Gay, K.; Johnson, J.; Mackinson, C.; Debess, E.; Madden, J.; Angulo, F.; Zervos M.J. (2003). Molecular characterization of gentamicin-resistant Enterococci in the United States: evidence of spread from animals to humans through food. J. Clin. Microbiol. 41, 1109-1113.

4. Eaton, T.J.; Gasson M.J. (2001). Molecular screening of Enterococcus virulence determinants and potential for genetic exchange between food and medical isolates. Appl. Environ. Microbiol. 67, 1628-1635.

5. Facklam, R.R.; Carvalho, M.RG.S.; Lucia, M.T. (2002) History, taxonomy, biochemical characteristics, and antibiotic susceptibility 
testing of enterococcis. In: Gilmore, M.S. (ed.). The Enterococci: Pathogenesis, Molecular Biology, and Antibiotic Resistance. ASM Press, Washington DC, USA. p. 1-55.

6. Franz, C.M.; Stiles, M.E.; Schleifer, K.H.; Holzapfel W.H. (2003). Enterococci in foods - a conundrum for food safety. Int. J. Food Microbiol. 88, 105-122.

7. Giraffa, G.; Carminati, D.; Neviani E. (1997). Enterococci isolated from dairy products: a review of risks and potential technological use. J. Food Protec. 60, 732-738.

8. Gold, H.S.; Moellering Jr., R.C. (1996). Antimicrobial-drug resistance. N. Engl. J. Med. 335, 1445-1453.

9. Hagen, R.M.; Gauthier, Y.P.; Sprague, L.D.; Vidal, D.R.; Zysk, G.; Finke, E.J.; Neubauer, H. (2002). Strategies for PCR based detection of Burkholderia pseudomallei DNA in paraffin wax embedded tissues. Mol. Pathol. 55, 398-400.

10. Hart, S.W.; Heuzenroeder, M.W.; Barton, M.D. (2004). Antimicrobial resistance in Campylobacter spp., Escherichia coli and Enterococcus, associated with pigs in Australia. J.Vet. Med. 51, 216-221.

11. Kayser, F.H. (2003). Safety aspects of enterococci from the medical point of view. Int. J. Food Microbiol. 88, 255-262.

12. Ke, D.; Picard, F.J.; Martineau, F.; Ménard, C.; Roy, P.H.; Ouelleette, M.; Bergeron, M.G. (1999). Development of a PCR assay for rapid detection of Enterococci. J. Clin. Microbiol. 37, 3497-3503.
13. Malani, P.N.; Kauffman, C.A.; Zervos, M.J. (2002) Enterococcal disease, epidemiology and treatment. In: Gilmore, M.S. (ed.). The Enterococci: Pathogenesis, Molecular Biology, and Antibiotic Resistance. ASM Press, Washington DC, USA. p. 385-408.

14. Marcinek, H.; Wirth, R.; Muscholl-Silberhorn, A.; Gauer, M. (1998). Enterococcus faecalis Gene Transfer under Natural Conditions in Municipal Sewage Water Treatment Plants. Appl. Environ. Microbiol. 64(2), 626-632.

15. Moyaert, H.; De Graef, E.M.; Haesebrouck, F.; Decostere, A. (2006). Acquired antimicrobial resistance in the intestinal microbiota of diverse cat populations. Res.Vet. Science. 81, 1-7.

16. National Committee on Clinical Laboratory Standards. (2002). Performance Standards for Antimicrobial Susceptibility Testing, $12^{\text {th }}$ Informational Supplement. National Committee on Clinical Laboratory Standards. Wayne, P.A.

17. Shepard, B.D.; Gilmore, M.S. (2002). Antibiotic-resistant enterococci: the mechanisms and dynamics of drug introduction and resistance. Microbes Infect. 4, 215-224.

18. Spelina. V.; Achlemmerová, L.; Landfeld, A.; Kyhos, K.; Mericka, P.; Houska, M. (2007) .Thermal inactivation of Enterococcus faecium. Czech J Food Sci. 25: 283-290. 